\title{
.
}

\section{CARACTERIZAÇÃO DE MASSAS REFRATÁRIAS UTILIZADAS COMO REPARO DE SEDE EM PANELAS DE ACIARIA ELÉTRICA*}

\section{Resumo}

Bruno Wartchow Laidens ${ }^{1}$ Bruna Berti de Sousa ${ }^{2}$ Ricardo Thomé da Cruz ${ }^{3}$ Saulo Roca Bragança ${ }^{4}$

Massas de reparo à quente de sede de válvula e de plugue em panela de aço são utilizadas a fim de se aumentar a vida útil dessas peças, as quais necessitam longo tempo para a troca. Isto propicia um ganho considerável na campanha da panela. $\mathrm{O}$ objetivo do presente trabalho foi a caracterização técnica das massas refratárias, bem como a seleção da massa mais adequada para utilização na panela de aço na Usina Rio-grandense. Uma massa magnesiana e duas aluminosas (concretos) foram analisadas por meio de diversas técnicas, como análise de imagens (lupa eletrônica e MEV), distribuição granulométrica, porosidade, composição química, análise mineralógica, resistência à compressão e teste de tração de aderência entre o substrato e a massa. Os resultados demonstraram que a massa de reparo magnesiana com resina de cura à quente apresentou os melhores resultados de adesão junto às sedes, além de apresentar uma significativa resistência à compressão.

Palavras-chave: Massas refratárias; Sede de plug; Reparo; Aciaria.

\section{CHARACTERIZATION OF UNSHAPED REFRACTORY MATERIALS USED TO REPAIR WELL BLOCKS IN STEEL LADLE}

\begin{abstract}
Refractory mixes used for the hot repair of the valve and the plug well blocks increase the lifespan of steel ladles in several campaigns. The extend life of these parts is very important, due to the long time they need to be changed and to return to operation. The objective of this study was the technical characterization of the refractory mixes as well as the selection of the most suitable mix for use in the steel ladle in Rio-grandense plant. A magnesian mass and two aluminous castables were analyzed using various techniques such as image analysis (electronic microscope and SEM), particle size distribution, chemical composition, mineralogical analysis, compressive strength and adhesion tensile test between the substrate and the mix. The results showed that the magnesian repair mass with the hot-cure resin showed the best adhesion results with the well blocks, and provide significant resistance to compression.
\end{abstract}

Keywords: Unshaped refractory; Well block; Hot repair; Steel mill.

1 Engenheiro de Materiais, Bacharel, estagiário, Aciaria Elétrica Gerdau Rio-grandense, UFRGS, Porto Alegre, Rio Grande do Sul - Brasil.

2 Engenheira de Materiais, Bacharel, Estudante de Mestrado do Programa de Pós Graduação em Engenharia de Minas, Metalúrgia e Materiais - PPG3M, UFRGS, Porto Alegre, Rio Grande do Sul - Brasil

3 Engenheiro de Materiais, Doutor. Programa de Pós Graduação em Engenharia de Minas Metalúrgica e Materiais - PPG3M, UFRGS, Porto Alegre, Rio Grande do Sul - Brasil

4 Engenheiro Químico, Doutor, Professor, DEMAT, UFRGS, Porto Alegre, Rio Grande do Sul Brasil. 


\section{INTRODUÇÃO}

A sede de plugue ou válvula é uma peça constituinte do sistema de rinsagem ou do sistema de válvula gaveta, respectivamente, de panelas de aciaria, como mostrado na Figura 1. A sede de plugue é produzida em concreto aluminoso e durante o processo produtivo a sede sofre desgaste. Em operação é aceitável um tamanho de sede mínimo (residual de segurança) de acordo com o tamanho requerido para funcionamento de um plugue de rinsagem. Com o objetivo de evitar o desgaste excessivo da sede são feitos reparos periodicamente, adicionando-se massa refratária sobre a mesma, prolongando assim sua vida útiL.

As massas de reparo usadas são materiais refratários não-conformados cujas propriedades físicas dependem da qualidade da instalação, cura/secagem, manuseio e armazenagem. Essas massas podem ser fornecidas prontas para uso ou secas, para serem misturadas com água na planta. Além disso, elas têm características diversas, tornando-as especificamente mais adequadas para determinadas aplicações. Para o reparo à quente, normalmente se utilizam argamassas, concretos auto-escoantes e massas de projeção. Dentre os materiais utilizados, os mais comuns são os concretos de alumina ou de zircônia, a fim de propiciar elevada resistência à abrasão ${ }^{12}$.
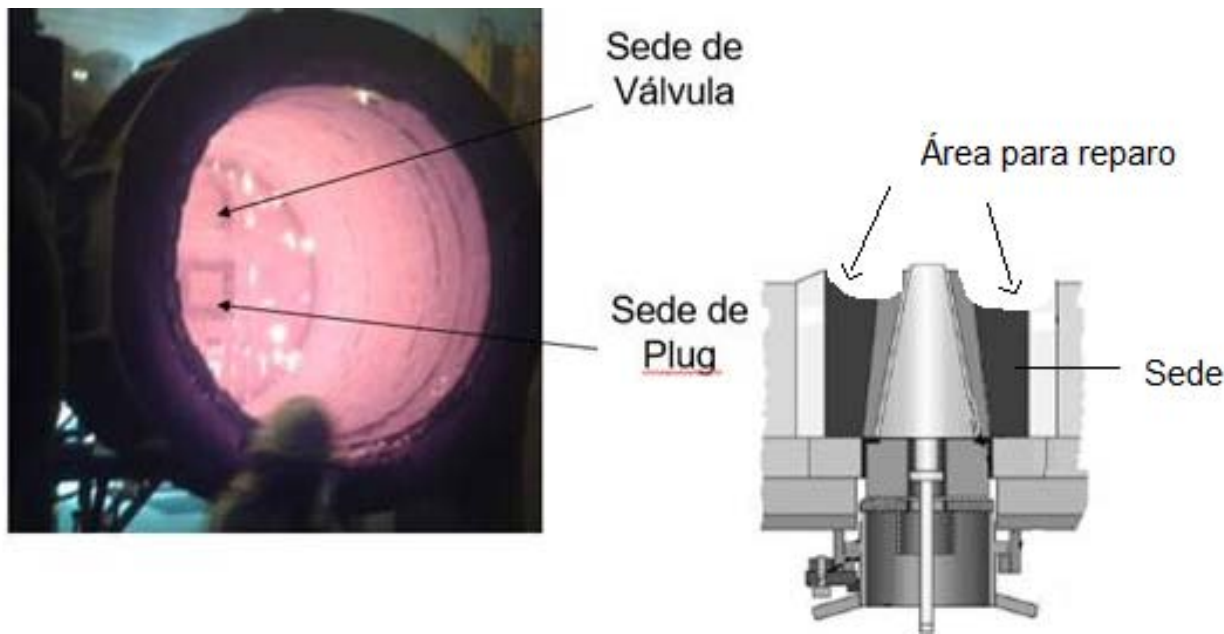

Figura 1: Posição das sedes de válvula e de plugue, o reparo é aplicado sobre as sedes, protegendo-as do desgaste.

No presente trabalho, realizou-se a caracterização técnica e microestrutural de diferentes massas refratárias, procurando-se avaliar as propriedades das massas e a metodologia proposta, a fim de selecionar a melhor massa para reparo de sede. Esses dados foram analisados com os testes de desempenho das massas na indústria.

\section{MATERIAIS E MÉTODOS}

Três massas de reparo de sede de dois fornecedores $A$ e $B$ foram avaliadas. Duas massas aluminosas secas, Al-A e Al-B, as quais foram misturadas com água e homogeneizadas. A terceira massa, denominada Mag-A, é magnesiana e é fornecida pronta para aplicação (escoamento livre). As massas são aplicadas diretamente na sede vertendo-as do alto da panela aquecida $\left(900^{\circ} \mathrm{C}\right)$. 
As amostras das massas de reparo foram analisadas com uso de lupa eletrônica (software de análise de imagens) e microscopia eletrônica de varredura. A análise da distribuição granulométrica das massas foi realizada em peneiras ABNT e cálculo do diâmetro médio de partícula (método de Sauter). Foram feitos ensaios para obtenção da absorção de água, porosidade aparente e densidade das massas não sinterizadas e sinterizadas, em quintuplicata. A composição química foi analisada por Fluorescência de raios $X(F R X)$ semi-quantitativa e análise mineralógica por Difração de raios $X(D R X)$.

As análises de resistência à compressão foram feitas em triplicata de corpos de prova cilíndricos não sinterizados e sinterizados. Para o preparo dos corpos de prova das massas secas não sinterizados, Al-A e Al-B, o material foi misturado com $12 \%$ de água, conformado em molde e deixado a temperatura ambiente, cerca de $22^{\circ} \mathrm{C}$, por $72 \mathrm{~h}$. Já no preparo do corpo de prova da massa fornecida pronta para aplicação, Mag-A, foi necessário colocar o molde contendo a massa na estufa a $120^{\circ} \mathrm{C}$ por 24 horas, uma vez que a presença de resinas na massa faz com que ela escoe ao ser desmoldada a temperatura ambiente, diferente do que ocorreu com as demais. As amostras sintetizadas, após passarem pelo mesmo processo das não sinterizadas, foram colocadas em forno a $1400^{\circ} \mathrm{C}$, por $120 \mathrm{~min}$ com taxa de aquecimento de $300^{\circ} \mathrm{C} / \mathrm{h}$. O teste de resistência à compressão foi realizado com taxa de $5 \mathrm{~mm} / \mathrm{min}$.

Devido à carência de normas técnicas para determinação de aderência à tração de revestimentos refratários, essa avaliação teve como base a metodologia utilizada para ensaiar

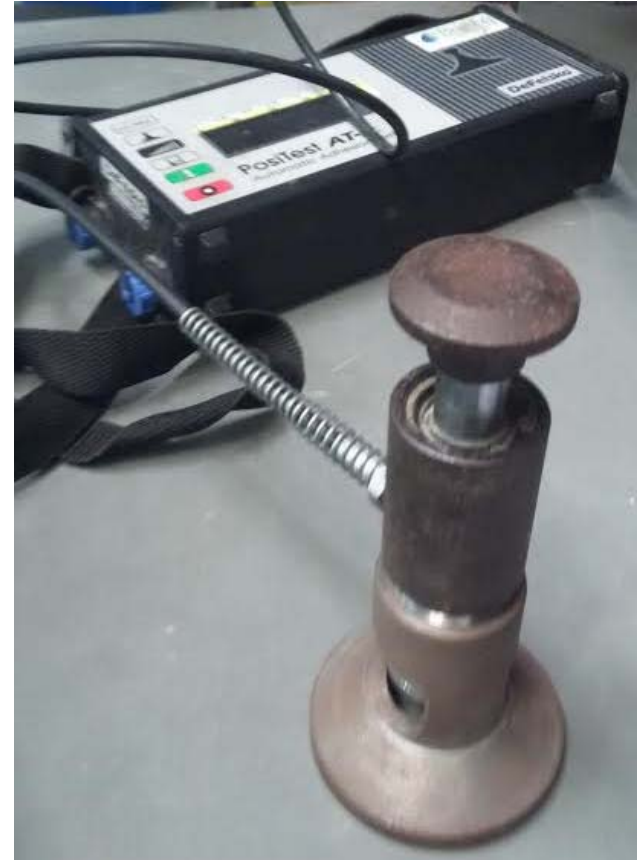

Figura 2. Equipamento utilizado no teste de Determinação de aderência à tração (PosiTest ATA Automatic Adhesion Tester DeFelsko) concretos convencionais (NBR 13528), cujo equipamento usado é ilustrado na Figura 2. Para o ensaio da massa Mag-A foi preciso colocar a massa previamente em estufa a $120^{\circ} \mathrm{C}$.

A vida útil das massas utilizadas na indústria foi aferida visualmente conforme a experiência dos técnicos da empresa que determinam o número de corridas de utilização.

\section{RESULTADOS E DISCUSSÃO}

\subsection{Análise visual}

As massas Al-B e Al-A são semelhantes com agregados e matriz de granulometria fina, mas Al-B possui pequenas fibras poliméricas, observável em Lupa (Figura 3). $\mathrm{O}$ software Image-J foi utilizado para medir a espessura das mesmas, as quais apresentaram cerca de $0,03 \mathrm{~mm}$. Como é conhecido, as fibras poliméricas são utilizadas em massas e concretos refratários para facilitar o processo de secagem. A 
massa Mag-A tem aparência diferente das citadas anteriormente, já que é fornecida umedecida em sacos fechados hermeticamente.

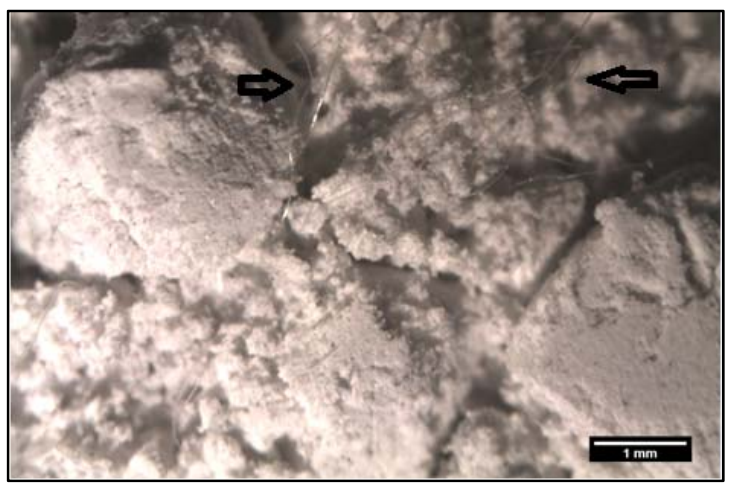

Figura 3. Imagem da massa de reparo de sede Al-B em Lupa (5x), em detalhe a presença de fibras

\subsection{Composição química}

As amostras de Al-A e Al-B apresentam em sua composição principalmente fases contendo alumínio e cálcio, típicas de concretos refratários aluminosos. Já a amostra de Mag-A é majoritariamente magnesiana, fases contendo $\mathrm{Mg}$, além de conter menores proporções de fases contendo $\mathrm{Si}, \mathrm{Al}$, Ca e $\mathrm{Fe}$, as quais provavelmente promovem a sinterização dos materiais em menores temperaturas.

\subsection{Análise mineralógica}

A análise mineralógica por DRX mostrou que Al-B e Al-A são compostas majoritariamente por alumina $\left(\mathrm{Al}_{2} \mathrm{O}_{3}\right)$ e aluminato de cálcio $\left(\mathrm{CaAl}_{2} \mathrm{O}_{4}\right)$ (Figura 4). Este compõe a matriz e é a parte responsável pela ligação (pega) do concreto. Já os agregados e partículas menores são de alumina, compõem o restante da massa e são os responsáveis pela resistência estrutural das peças. A massa de reparo MagA é a base de periclásio ( $\mathrm{MgO}$ ) (Figura 5 ) além de conter outras fases em menores proporções como corundum $\left(\mathrm{Al}_{2} \mathrm{O}_{3}\right)$, Óxido de Cálcio/Ferro, alumínio e silício, o que está de acordo com a composição química do material. 


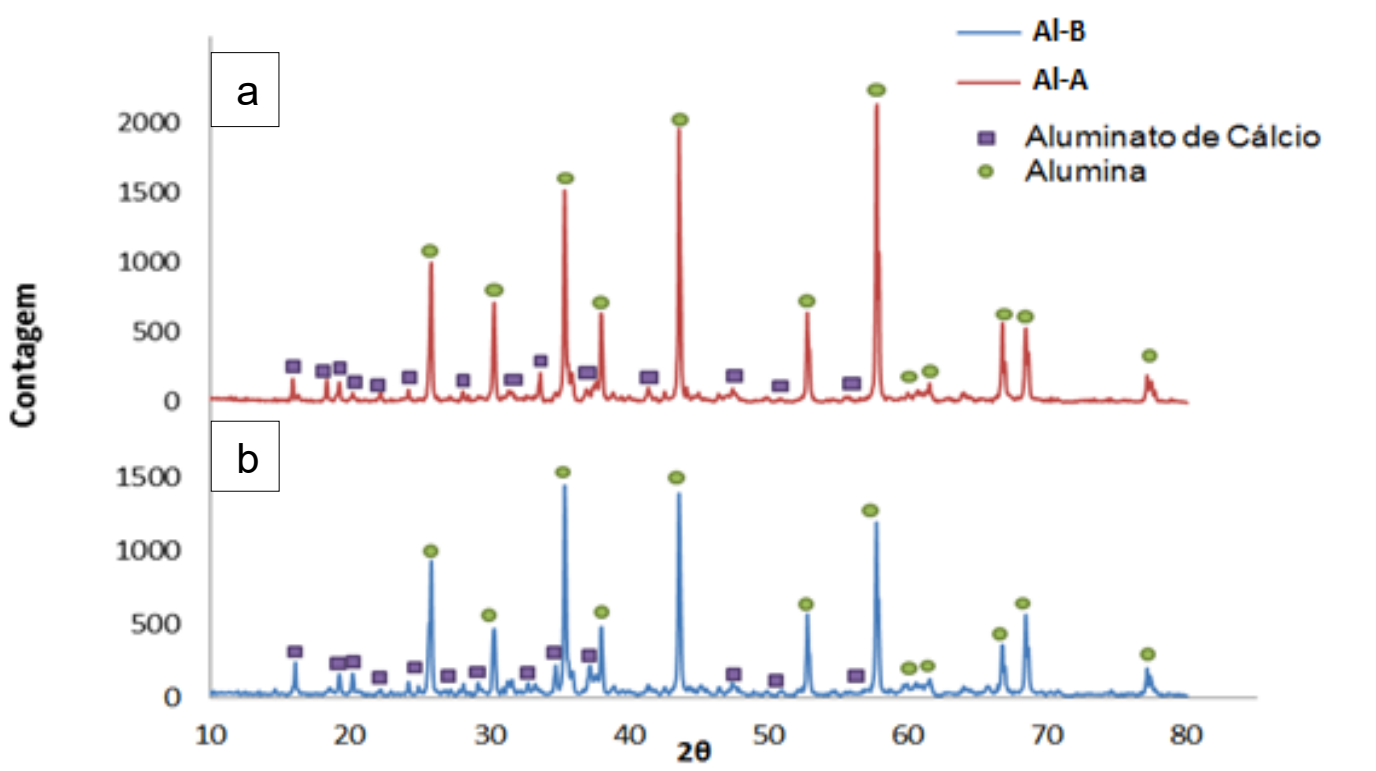

Figura 4. DRX da massa Al-A(a) e Al-B(b).

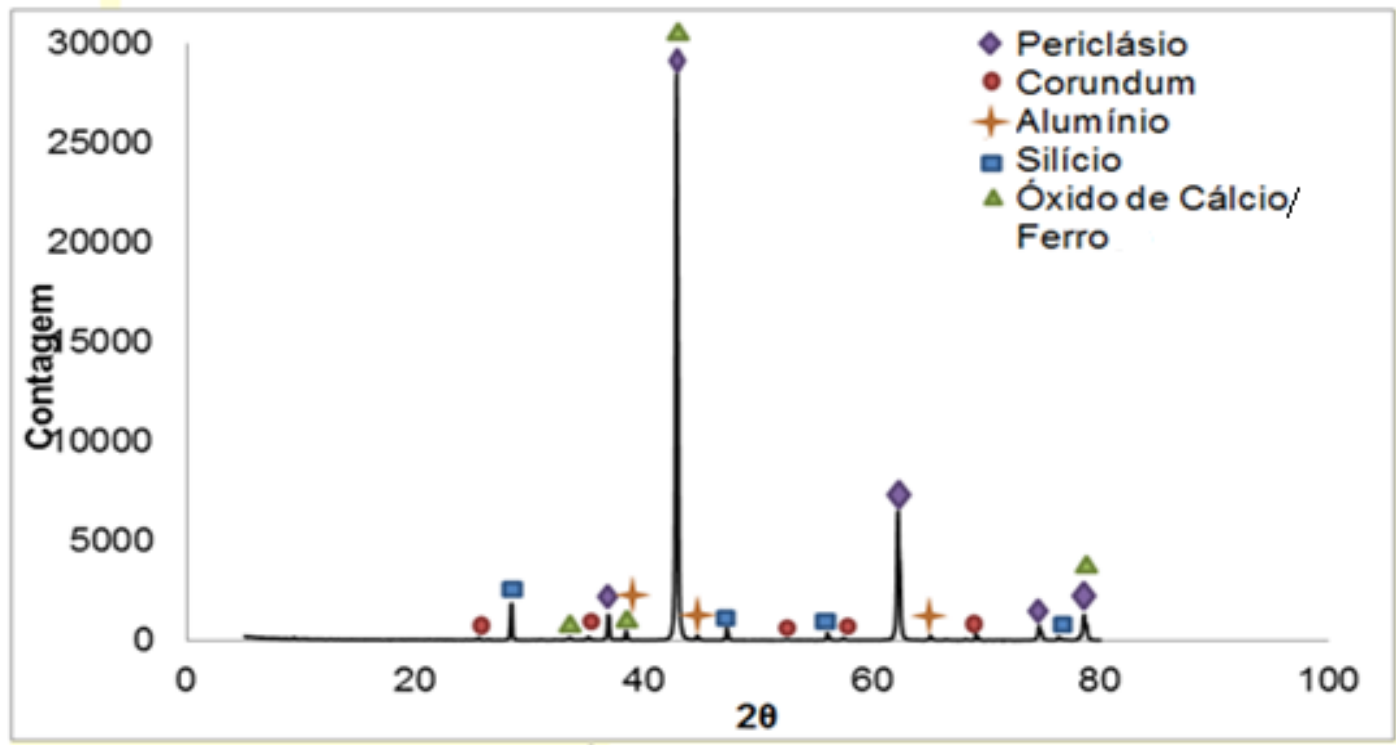

Figura 5. DRX da massa Mag-A.

\subsection{Granulometria}

O diâmetro médio de partículas das massas é mostrado na Tabela 1. Os resultados percentuais para cada faixa de tamanho de partícula da análise granulométrica indicaram que a massa Al-B tem maior fração de partículas finas, o que pode dificultar a secagem, mas pode ser compensado pela presença de fibras. Por outro lado, a menor granulometria pode facilitar o processo de sinterização.

Tabela 1. Resultados da análise granulométrica.

\begin{tabular}{|c|c|}
\hline Produto & Diâmetro médio de Sauter $(\mathrm{mm})$ \\
\hline Al-A & 0,095 \\
\hline Al-B & 0,049 \\
\hline Mag-A & ${ }^{*}$ \\
\hline
\end{tabular}

Obs: * a presença de resina dificulta a medição do tamanho de partículas. 


\subsection{Absorção de água, Porosidade e Densidade}

A Tabela 2 mostra que as massas Al-A e Al-B possuem valores próximos de porosidade e densidade, apesar da diferença das granulometrias das massas. Este fato se repetiu nas peças queimadas, as quais foram colocadas diretamente no forno. Isto se deve, portanto, ao efeito da saída da água durante a secagem, a qual abre a porosidade das peças. Os corpos de prova preparados na temperatura ambiente apresentam menor absorção de água e menor porosidade aparente que as queimadas a $1400^{\circ} \mathrm{C}$. Portanto, a queima das peças úmidas até $1400^{\circ} \mathrm{C}$, propiciou uma maior porosidade aberta. A maior porosidade do Al-B em relação ao Al-A pode ser explicada tanto pela maior fração de finos, que dificultam a evaporação de água gerando poros na estrutura, não sendo compensado pela presença de fibras. A porosidade resultante dos ensaios Mag-A é similar a das demais massas.

Tabela 2. Resultados obtidos para absorção de água, porosidade aparente e densidade das diferentes massas Al-A, Al-B, Mag-A preparadas a temperatura ambiente e após queima a $1400^{\circ} \mathrm{C}$.

\begin{tabular}{|c|c|c|c|c|}
\hline Análise & \multicolumn{4}{|c|}{ Amostras } \\
\hline \multirow{4}{*}{$\begin{array}{c}\text { Absorção } \\
\text { de água } \\
(\%)\end{array}$} & \multicolumn{2}{|c|}{ Temperatura ambiente } & \multicolumn{2}{|c|}{ Queimadas a $1400^{\circ} \mathrm{C}$} \\
\hline & AL-A & $6,02 \pm 0,32$ & $A L-A$ & $7,24 \pm 0,40$ \\
\hline & $\mathrm{AL}-\mathrm{B}$ & $7,38 \pm 0,85$ & $\mathrm{AL}-\mathrm{B}$ & $8,32 \pm 0,54$ \\
\hline & Mag-A & * & Mag-A & $10,97 \pm 1,22$ \\
\hline \multirow{4}{*}{$\begin{array}{c}\text { Porosidade } \\
\text { Aparente } \\
(\%)\end{array}$} & \multicolumn{2}{|c|}{ Temperatura ambiente } & \multicolumn{2}{|c|}{ Queimadas a $1400^{\circ} \mathrm{C}$} \\
\hline & $\mathrm{AL}-\mathrm{A}$ & $17 \pm 0,81$ & $\mathrm{AL}-\mathrm{A}$ & $19,9 \pm 0,94$ \\
\hline & AL-B & $19,92 \pm 1,76$ & $\mathrm{AL}-\mathrm{B}$ & $22,2 \pm 0,10$ \\
\hline & Mag-A & * & Mag-A & $18,35 \pm 1,65$ \\
\hline \multirow{4}{*}{$\begin{array}{c}\text { Densidade } \\
\left(\mathrm{g} / \mathrm{cm}^{3}\right)\end{array}$} & \multicolumn{2}{|c|}{ Temperatura ambiente } & \multicolumn{2}{|c|}{ Queimadas a $1400^{\circ} \mathrm{C}$} \\
\hline & AL-A & $2,82 \pm 0,02$ & $\mathrm{AL}-\mathrm{A}$ & $2,75 \pm 0,03$ \\
\hline & $A L-B$ & $2,7 \pm 0,076$ & AL-B & $2,67 \pm 0,04$ \\
\hline & Mag-A & * & Mag-A & $1,68 \pm 0,073$ \\
\hline
\end{tabular}

Obs: * a presença de resina dificulta a medição na temperatura ambiente.

\subsection{Análise Microestrutural das massas sinterizadas a $1400^{\circ} \mathrm{C}$}

As imagens em MEV das massas Al-B e Al-A (composição via EDS no quadro inserido nas Figuras 6 e 7) indicam que elas possuem microestruturas muito semelhantes, apresentando uma boa distribuição de agregados e matriz de alumina (partículas pequenas e aluminato de cálcio). Como demonstrado nas análises anteriores, não há diferenças significativas entre as massas dos dois fabricantes.

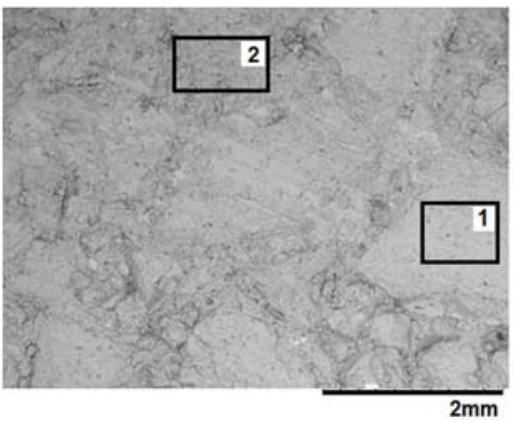

\begin{tabular}{ccc}
\hline Elemento & Área 1 & Área 2 \\
\hline Carbono & 5,72 & 10,82 \\
Oxigênio & 51,28 & 53,33 \\
Alumínio & 42,42 & 32,79 \\
Cálcio & 0,21 & 2,76 \\
\hline
\end{tabular}

Figura 6 - Microestruturas (MEV) e composição química elementar pontual (EDS) da massa Al-B sinterizada a $1400^{\circ} \mathrm{C}$ 


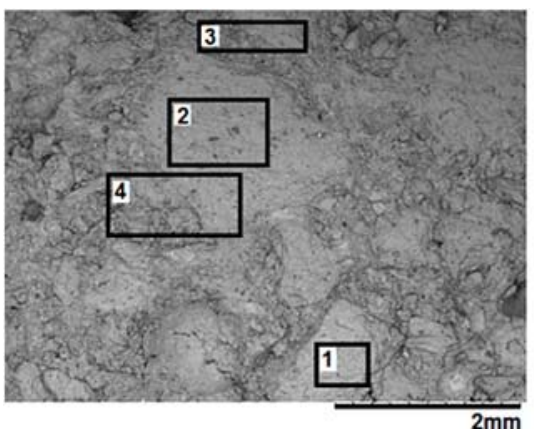

\begin{tabular}{ccccc}
\hline Elemento & Área 1 & Área 2 & Área 3 & Área 4 \\
\hline Carbono & - & 9,85 & 5,42 & 7,39 \\
Oxigênio & 52,58 & 49,20 & 51,71 & 51,9 \\
Alumínio & 46,19 & 40,04 & 37,27 & 36,38 \\
Magnesiano & 0,28 & - & - & - \\
Cálcio & 0,52 & 0,40 & 5,21 & 3,97 \\
\hline
\end{tabular}

Figura 7 - Microestruturas (MEV) e composição química elementar pontual (EDS) da massa $\mathrm{Al}-\mathrm{A}$ sinterizada a $1400^{\circ} \mathrm{C}$.

A massa Mag-A é claramente a que apresenta maior quantidade de impurezas (Figura 8). $\mathrm{Na}$ área 1 destaca-se a presença de titânio. Os agregados são predominantemente de magnésia e a matriz de cimento de alumina e, possivelmente, silicatos de cálcio (e/ou alumino-silicato de cálcio), silicato de ferro e partículas menores de MgO.

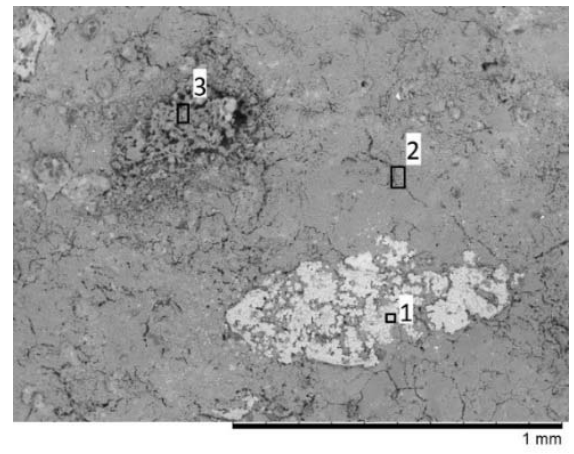

\begin{tabular}{cccc}
\hline Elemento & Area 1 & Area 2 & Area 3 \\
\hline Carbono & 8,447 & 11,562 & 9,839 \\
Oxigênio & 43,835 & 40,942 & 43,442 \\
Magnésio & 20,590 & 44,395 & 36,438 \\
Alumínio & 1,460 & - & 2,908 \\
Silício & 1,548 & 0,292 & 1,573 \\
Cálcio & 2,547 & - & 0,798 \\
Titânio & 15,060 & 0,435 & 1,541 \\
Ferro & 6,514 & 1,011 & 3,461 \\
\hline
\end{tabular}

Figura 8 - Microestruturas (MEV) e composição química elementar pontual (EDS) da massa Mag-A sinterizada a $1400^{\circ} \mathrm{C}$.

\subsection{Resistência à compressão}

Os resultados na Tabela 3 para os corpos de prova Al-B e de Al-A (Figura 9a e 9b, respectivamente) apresentam resistência mecânica significativa quando preparados à temperatura ambiente.

Após a queima a $1400^{\circ} \mathrm{C}$ a resistência mecânica depende da ligação cerâmica, bem como da presença de poros e defeitos estruturais. A Al-A apresentou resistência maior que a similar, Al-B, o que pode ser atribuído a maior porosidade da massa do fabricante $B$, a qual apresentou maior porosidade após a queima além de perder $\sim 33 \%$ de resistência mecânica em relação à temperatura ambiente. No entanto, o valor de resistência é considerado bom para ambas as massas.

Salienta-se que a resistência após a queima a $1400^{\circ} \mathrm{C}$ depende também da forma de aquecimento e da taxa de aquecimento no forno de laboratório. A taxa usada foi de $300^{\circ} \mathrm{C} / \mathrm{h}$, a qual que pode causar danos ou desenvolver poros maiores, devido à rápida evaporação e saída de água.

Em condições de operação, as taxas de aquecimento são ainda mais elevadas (já que a massa de reparo é vertida na panela quente $\sim 900^{\circ} \mathrm{C}$ ). Salienta-se também que em temperaturas superiores $\left(\sim 1600^{\circ} \mathrm{C}\right.$ em contato com aço) a sinterização pode 
aumentar a densificação e, consequentemente, propiciar uma maior resistência das massas (na superfície).

A massa Mag-A apresentou valores intermediários de resistência à compressão em relação às massas aluminosas. Portanto, a formação de porosidade é fator determinante da resistência mecânica e esta depende da metodologia de teste. Observa-se que esse fator pode resultar em valores de resistência à compressão diferentes dos dados reais.

Tabela 3. Médias dos resultados de resistência à compressão. Al-A, Al-B e Mag-A.

\begin{tabular}{|c|c|c|}
\hline Condições & Produto & Resistência a compressão (MPa) \\
\hline \multirow{2}{*}{$1400^{\circ} \mathrm{C}$} & $\mathrm{Al}-\mathrm{A}$ & $22,34 \pm 7,70$ \\
\cline { 2 - 3 } & $\mathrm{Al}-\mathrm{B}$ & $10,28 \pm 5,61$ \\
\cline { 2 - 3 } & $\mathrm{Mag}-\mathrm{A}$ & $13,75 \pm 1,70$ \\
\hline \multirow{2}{*}{$\begin{array}{c}\text { Temperatura } \\
\text { ambiente }\end{array}$} & $\mathrm{Al}-\mathrm{A}$ & $21,82 \pm 4,40$ \\
\cline { 2 - 3 } & $\mathrm{Al}-\mathrm{B}$ & $15,52 \pm 4,42$ \\
\cline { 2 - 3 } & $\mathrm{Mag}-\mathrm{A}$ & ${ }^{*}$ \\
\hline
\end{tabular}

Obs: ${ }^{*}$ valor não medido.
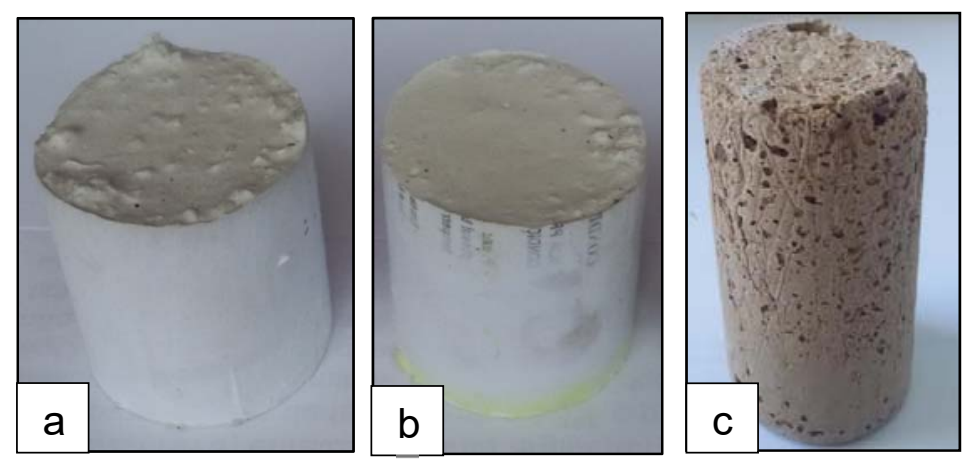

Figura 9. Corpos de prova para ensaio de compressão das massas Al-B (a), Al-A(b) e Mag-A (c)

\subsection{Adesividade}

A massa $\mathrm{Al}-\mathrm{A}$, tanto preparada à temperatura ambiente $^{3}$ (Figura 10a), quanto à $1400^{\circ} \mathrm{C}$ (Figura $10 \mathrm{~b}$ ), perdeu aderência do substrato ainda durante o manuseio. $\mathrm{O}$ mesmo aconteceu com a massa Al-B.

A massa Mag-A foi preparada a $120^{\circ} \mathrm{C}$, uma vez que não endurece a temperatura ambiente. Ela, além não perder a aderência durante o manuseio, apresentou alta resistência no teste de resistência a tração da aderência, 2,85 MPa, valor superior ao das argamassas de revestimento usadas na indústria da construção civil, cuja resistência de aderência à tração média varia de 0,11 a 0,25 $\mathrm{MPa}$.

A Figura 10c mostra a massa Mag-A aderida com os cilindros de tração e demonstra como a fratura ocorreu no corpo da massa e não na interface entre a massa e o substrato, indicando que a resistência na interface é superior à da própria massa.

Nos testes industriais se verificou que o reparo das massas testadas se desgasta gradualmente. No entanto o reparo das massas Al-A e Al-B, ocasionalmente, era perdido devido à falta de aderência, fato que não ocorreu com a Mag-A. Assim, o teste de resistência à tração da aderência é crucial para a determinação da massa mais adequada para a esta aplicação. 


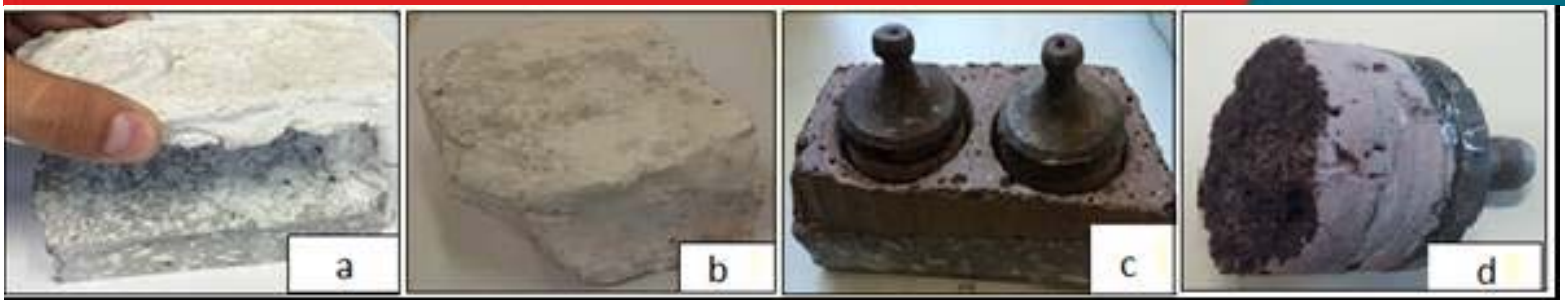

Figura 10. Massas de reparo sobre a sede. (a) AL-A a temperatura ambiente (b) Al-A após queima a $1400^{\circ} \mathrm{C}$ (c) Mag-A após cura a $120^{\circ} \mathrm{C}$ preparada para o ensaio de adesividade e (d) superfície rompida

\section{CONCLUSÃO}

As massas aluminosas de reparo de sede Al-A e Al-B apresentaram propriedades similares quanto à composição química, mineralogia e microestrutura. A Al-B possui granulometria mais fina e presença de fibras poliméricas. A saída de água e, consequente geração de poros, foi considerada o fator determinante da porosidade e resistência mecânica após secagem e após a queima. Isso foi observado após a queima em $1400^{\circ} \mathrm{C}$, uma vez que a porosidade aparente da amostra Al-B é maior (22\%) e a resistência à compressão é menor ( 10 MPa) que os respectivos valores para a massa Al-A, (20\% e $22 \mathrm{MPa}$, respectivamente). No entanto, ambas apresentaram resistência à compressão elevada à temperatura ambiente (Al-A 22MPa e Al-B 15MPa).

O ensaio de resistência à compressão indica que a $\mathrm{Al}-\mathrm{A}$ e $\mathrm{Al}-\mathrm{B}$ tem boas propriedades estruturais, no entanto, essas massas dependem muito da ligação cerâmica em elevada temperatura, podendo desprender da sede antes de atingirem a resistência final.

No teste de resistência a tração da aderência, o melhor resultado foi o da Mag-A preparada a $120^{\circ} \mathrm{C}$, a qual resistiu a $2,85 \mathrm{MPa}$. Testes da Mag-A na planta confirmaram que ela dificilmente se desprende do substrato (sede), o que gera um revestimento de longa vida útil ( 18 corridas). As outras massas, $\mathrm{Al}-\mathrm{A}$ e $\mathrm{Al}-\mathrm{B}$, não apresentaram resistência suficiente à realização do teste de aderência. Em uso industrial, em algumas ocasiões, elas perderam a ligação com o substrato, ou seja, ficou exposta a sede (degradada), o que não é desejado.

A Mag-A apresentou valores intermediários de resistência à compressão, em relação às outras massas, mas com menor dispersão de valores. Como dito, ela destacou-se ainda pela maior resistência de aderência. Assim, além dos testes tradicionais de avaliação da resistência mecânica, recomenda-se também o teste de aderência.

Em testes industriais, a massa Mag-A apresentou o melhor desempenho, considerando o custo das massas, a quantidade necessária para fazer o reparo e sua confiabilidade. $O$ uso da Mag-A gera ganhos financeiros de cerca de $12,5 \%$ quando comparado ao uso das massas Al-A ou Al-B.

\section{Agradecimentos}

NORIE - Núcleo Orientado para a Inovação da Edificação - UFRGS

\section{REFERÊNCIAS}

1 C.A. Schatcht, Marcel Dekker INC, Refractories Handbook, 2004, 109

2 A.M. Segadães, Refractários. Universidade de Aveiro, 1997

3 ABNT, NBR 13528:Revestimento de paredes e tetos de argamassas inorgânicas Determinação da resistência de aderência a tração,1995 